\title{
Cannabis use among middle and high school students in Ontario: a school-based cross-sectional study
}

\author{
Hugues Sampasa-Kanyinga MD MSc, Hayley A. Hamilton PhD, Allana G. LeBlanc PhD, \\ Jean-Philippe Chaput $\mathrm{PhD}$
}

\section{Abstract}

Background: Cannabis use can have serious detrimental effects in children and adolescents. It is therefore important to continually assess the use of cannabis among young people in order to inform prevention efforts. We assessed the prevalence of cannabis use among middle and high school students in Ontario and examined its association with demographic and behavioural factors.

Methods: Data were obtained from the 2015 Ontario Student Drug Use and Health Survey, a province-wide school-based survey of students in grades 7 through 12. Analyses included a representative sample of 9920 middle and high school students. Bivariate cross-tabulations and logistic regression analyses were used to investigate the factors associated with cannabis use.

Results: Overall, $21.5 \%$ and $13.9 \%$ of students reported using cannabis in the previous year and previous month, respectively. The conditional probability that an adolescent who reported cannabis use in the previous year would report daily use was $12.5 \%$. There was a significant dose-response gradient with age, with older students being more likely to use cannabis than younger students. In multivariable analyses, being in grades 10 through 12 (odds ratios [ORs] ranged from 3.71 to 3.85), being black (OR 2.67 [95\% confidence interval $(\mathrm{Cl})$ 1.76-4.05]), using tobacco cigarettes (OR 10.10 [95\% Cl 8.68-13.92]) and being an occasional (OR 5.35 [95\% Cl 4.01-7.13]) or regular (OR 14.6 [95\% Cl 10.8-19.89]) alcohol user were associated with greater odds of cannabis use. Being an immigrant was associated with lower odds of cannabis use (OR 0.55 [95\% Cl 0.39-0.78]).

Interpretation: The findings suggest that cannabis use is prevalent among middle and high school students in Ontario and is strongly associated with tobacco cigarette smoking and alcohol consumption. Future research should document trends in cannabis use over time, including its risks, especially when the legalization of recreational cannabis comes into effect.

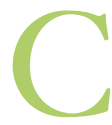
annabis use can have serious detrimental effects in children and adolescents. ${ }^{1-5}$ Furthermore, it is constantly changing. ${ }^{6}$ As observed with cigarette smoking, ${ }^{7}$ newer methods, such as vaping, digesting or changing supply, and changes in the perception of the risk associated with cannabis are alarming. ${ }^{7-9}$ It is therefore important to continually assess the use of cannabis among young people in order to inform prevention efforts. Monitoring drug use also provides valuable information about potential determinants (established and emerging) of cannabis use and co-use of cannabis with alcohol, tobacco and/or other drugs. These data could enable the evaluation of the effectiveness of policies and education programs. Research has shown that the values and lifestyles of adolescents change quickly, ${ }^{10}$ and close monitoring can help to ensure that program responses are based on empirical evidence.

Several important initiatives have been undertaken to tackle cannabis use in Canada, including the lower-risk cannabis use guidelines, which were released in June 2017 to protect public health and safety. ${ }^{11}$ The government of Canada has committed to legalizing the use, possession, purchase and growth of recreational cannabis by July 2018. It is therefore crucial to gain more understanding on sociodemographic characteristics and behavioural factors associated with cannabis use among adolescents because 1) cannabis is the most commonly used illegal drug among youth in Canada, ${ }^{12}$ 2) such knowledge could constitute baseline data necessary for surveillance and evaluation of the effects of legalization on patterns of cannabis use and related factors and 3 ) adolescents are more vulnerable to the adverse effects of cannabis than adults. ${ }^{13}$ Thus, the objective of this study was to assess the prevalence of cannabis use among

\section{Competing interests: None declared.}

This article has been peer reviewed.

Correspondence to: Hugues Sampasa-Kanyinga, hsampasa@ uottawa.ca

CMAJ Open 2018. DOI:10.9778/cmajo.20170159 
middle and high school students in Ontario and to examine the association with demographic and behavioural factors. We hypothesize that cannabis use is prevalent among middle and high school students and is associated with sociodemographic characteristics and other substance use.

\section{Methods}

\section{Setting, design and participants}

We obtained data from the 2015 Ontario Student Drug Use and Health Survey, a province-wide school-based crosssectional survey of students in grades 7-12 within the public or Catholic school system. ${ }^{12}$ This survey has been conducted every 2 years since 1977 and is the longest ongoing school survey in Canada. It uses a 2-stage cluster design involving a random selection of classes from within a random selection of schools (probability proportional to size) stratified by region and school type. The survey is administered in classrooms through anonymous, student-completed questionnaires. Of the 349 schools that were invited to participate, 220 schools from 43 school boards participated in the survey, resulting in a school participation rate of $63 \%$. The most common reasons given by nonparticipating schools were that they were too busy or that they had already committed to other research projects. A total of 10426 students (representing nearly 900000 students in grades 7-12) from 750 classes participated in the 2015 cycle of the survey. The response rate for students was $59 \%$. Student nonresponse was due to absenteeism (11\%), unreturned consent forms or parental refusal (29\%) and other reasons such as comprehension issues or withdrawal (1\%). Further details regarding the study design are available elsewhere. ${ }^{12}$ All participants provided their own assent in addition to parental signed consent.

\section{Measures}

\section{Cannabis use}

Items measuring cannabis use were adapted from the Centers for Disease Control and Prevention's Youth Risk Behaviour Survey. ${ }^{12}$ Past-year cannabis use was based on a survey question asking about the frequency of cannabis use in the previous 12 months. Cannabis was also referred to as marijuana, hashish, hash oil, "pot," "weed," "grass" and "hash." Respondents were provided with 8 response choices. Responses were collapsed to create a binary (yes/no) measure of cannabis use: respondents who indicated that they had used cannabis at least once in the previous 12 months were classified as having used cannabis ("yes"), and those who had not used cannabis in the 12 months before the survey, who had never used cannabis or who reported that they did not know what cannabis is were classified as not having used cannabis in the previous 12 months ("no"). A similar item was used to assess recent cannabis use. Responses were collapsed 3 different ways to create 3 binary (yes/no) measures of cannabis use: 1) pastmonth use (use at least once in the previous $4 \mathrm{wk}$ ), 2) use on a weekly basis (use at least once each week) and 3) use on a daily basis (use at least once each day).
Synthetic cannabis use was based on a survey question asking about the frequency of synthetic cannabis use in the previous 12 months. Synthetic cannabis was referred to as "SPICE," also known as "K2," "K3," "Blaze," "Black Mamba," "legal weed," "fake pot" and "IZMS." For both the past-year and lifetime measures, responses were collapsed to create a binary (yes/no) measure of synthetic cannabis use.

Students were also asked about their history with cannabis use and were asked to indicate the grade they were in when (if ever) they first tried cannabis. Respondents were provided with 10 response options. First use of cannabis in grade 4 or before, grade 5 and grade 6 were collapsed for analysis.

\section{Other substance use}

Previous-year smoking of tobacco cigarettes (excludes a few puffs) was constructed as a dichotomous measure (yes/no). Alcohol use in the previous 12 months was constructed as a 3-category measure: "nonuse," "special occasion use" or "regular use." Students who had never drunk alcohol, had not drunk in the previous 12 months or had had only a sip of alcohol were classified as "nondrinkers." Drinking on special occasions was classified as occasional drinking. Drinking outside of special occasions (i.e., from once a month or less to almost every day [6 or 7 times a week]) was classified as regular drinking.

\section{Sociodemographic characteristics}

Sociodemographic characteristics included sex (male/female), grade (7-12, with grades 7 and 8 collapsed to increase statistical power), racial background (white, black, East/South East Asian, South Asian or other), subjective socioeconomic status (low v. high) ${ }^{14}$ and immigration status (immigrant/nonimmigrant).

\section{Physical activity, screen time and sleep duration}

Physical activity, screen time and sleep duration were categorized as a binary measure (meeting or not meeting current guidelines ${ }^{15,16}$ ). The guideline for physical activity was $60 \mathrm{~min}-$ utes or more of moderate to vigorous physical activity per day; for screen time, 2 hours or less of recreational screen time per day; and for sleep duration, 9-11 hours per night for those aged 11-13, 8-10 hours per night for those aged 14-17 and 7-9 hours per night for those aged 18 or more. ${ }^{16,17}$ Physical activity, screen time and sleep duration were self-reported as part of the questionnaire administered to students.

\section{Statistical analysis}

We used sampling weight and Taylor series linearization methods to account for the complex sample design of the survey. We generated descriptive statistics on the prevalence of cannabis use measured with the use of various timeframes. We used cross-tabulations to examine bivariate associations of cannabis use (lifetime, past-year and past-month) with sociodemographic and behavioural characteristics. We compared data using the Pearson $\chi^{2}$ test adjusted for the survey design and transformed into an $F$ statistic for categorical data, as well as an adjusted Wald test for continuous data. We performed univariable (model 1) and multivariable (models 2-4) 
logistic regression analyses to examine the relations between past-year cannabis use with demographic and behavioural factors, including sex, grade, ethnicity, socioeconomic status, immigration status, tobacco cigarette use, alcohol use, and adherence to the physical activity, screen time and sleep duration recommendations. All data were analyzed with Stata version 13.0 (StataCorp). Statistical significance was set at $p<$ 0.05 .

\section{Ethics approval}

The study was approved by the research ethics boards of the Centre for Addiction and Mental Health and York University, as well as existing research review committees of participating school boards.

\section{Results}

After removing missing data, we were left with an analytical sample of 9920 students, reducing our initial sample size by $4.9 \%$. Students with missing data were more likely to be male and in earlier grades. However, with-and-without analyses showed that excluded missing data from the analyses did not significantly affect the results.

Overall, $21.5 \%$ of students reported using cannabis at least once in the previous year (Table 1). Fewer students reported using cannabis on a monthly and daily basis $(13.9 \%$ and $2.8 \%$, respectively). The conditional probability that an adolescent who reported cannabis use in the past year would report daily use was $12.5 \%$. About $1 \%$ of students reported using synthetic cannabis at least once in the previous 12 months. Grades 9 and 10 were the most common grades in which students reported having tried cannabis for the first time.

Table 2 presents bivariable associations between cannabis use and demographic and behavioural factors among Ontario middle and high school students. There was a dose-response gradient with age, with older students being more likely to use cannabis than younger students. Cannabis use was more frequent among students who reported past-year tobacco cigarette use, those who reported occasional or regular alcohol use, and those with short sleep durations. The proportion of students who reported tobacco cigarette use in the previous year, $18.1 \%$, was similar to the proportion who reported pastyear cannabis use. Students of Asian ethnic background were less likely than those of other ethnic backgrounds to use cannabis, and immigrants were less likely to use cannabis than were nonimmigrants. Socioeconomic status was not significantly associated with cannabis use.

Table 3 presents univariable and multivariable logistic regression analyses examining the relations between cannabis use in the previous year and demographic and behavioural

\begin{tabular}{|c|c|c|}
\hline Variable & $\begin{array}{l}\text { Unweighted } \\
\text { count }\end{array}$ & $\begin{array}{l}\text { Weighted estimate } \\
\qquad(95 \% \mathrm{Cl}), \%\end{array}$ \\
\hline \multicolumn{3}{|l|}{ Cannabis use } \\
\hline Lifetime & 2087 & $24.1(21.7-26.5)$ \\
\hline Previous 12 mo & 1863 & $21.5(19.3-23.8)$ \\
\hline Previous month & 1142 & $13.9(12.2-15.7)$ \\
\hline Weekly & 396 & $4.9(4.0-5.8)$ \\
\hline Daily & 207 & $2.8(2.1-3.5)$ \\
\hline Don't know what cannabis is & 444 & $4.2(3.5-5.0)$ \\
\hline Never used cannabis in life & 7833 & $75.9(73.4-78.2)$ \\
\hline \multicolumn{3}{|l|}{ Synthetic cannabis use } \\
\hline Lifetime & 147 & $1.6(1.1-2.1)$ \\
\hline Previous 12 mo & 112 & $1.3(0.9-1.7)$ \\
\hline \multicolumn{3}{|l|}{ First time tried cannabis } \\
\hline Never tried & 7783 & $75.3(72.0-77.5)$ \\
\hline Grade 6 or before & 105 & $1.0(0.7-1.3)$ \\
\hline Grade 7 & 205 & $1.8(1.4-2.4)$ \\
\hline Grade 8 & 350 & $3.7(3.1-4.4)$ \\
\hline Grade 9 & 627 & $7.0(6.1-8.1)$ \\
\hline Grade 10 & 491 & $6.2(5.4-7.2)$ \\
\hline Grade 11 & 269 & $3.7(3.2-4.2)$ \\
\hline Grade 12 & 90 & $1.3(0.9-1.7)$ \\
\hline
\end{tabular}


Table 2: Bivariable associations between cannabis use and demographic and behavioural factors among Ontario middle and high school students*

\begin{tabular}{|c|c|c|c|c|c|}
\hline \multirow[b]{2}{*}{ Factor } & \multicolumn{5}{|c|}{ Cannabis use category; $† \%$ of respondents } \\
\hline & Total sample & Lifetime use & $\begin{array}{l}\text { Use in } \\
\text { previous } \\
12 \text { mo }\end{array}$ & $\begin{array}{l}\text { Use in } \\
\text { previous } \\
\text { month }\end{array}$ & $\begin{array}{l}\text { Never used in } \\
\text { life }\end{array}$ \\
\hline Age, mean $\pm S D, y r$ & $15.1 \pm 1.8$ & $16.4 \pm 1.2 \ddagger$ & $16.4 \pm 1.2 \ddagger$ & $16.4 \pm 1.2 \ddagger$ & $14.8 \pm 1.9$ \\
\hline \multicolumn{6}{|l|}{ Sex } \\
\hline Male & 51.3 & 25.5 & 22.4 & 15.0 & 74.5 \\
\hline Female & 48.7 & 22.6 & 20.7 & 12.8 & 77.4 \\
\hline \multicolumn{6}{|l|}{ Grade } \\
\hline $7 / 8$ & 25.7 & $3.4 \ddagger$ & $3.0 \ddagger$ & $2.2 \ddagger$ & 96.6 \\
\hline 9 & 16.1 & 11.9 & 10.1 & 6.6 & 88.1 \\
\hline 10 & 16.7 & 26.8 & 24.7 & 14.7 & 73.2 \\
\hline 11 & 17.3 & 38.8 & 34.7 & 23.5 & 61.2 \\
\hline 12 & 24.1 & 42.0 & 37.3 & 24.0 & 58.0 \\
\hline \multicolumn{6}{|l|}{ Ethnicity } \\
\hline White & 57.7 & $28.7 \ddagger$ & $25.4 \ddagger$ & $16.4 \ddagger$ & 71.3 \\
\hline Black & 7.0 & 26.8 & 25.0 & 17.3 & 73.2 \\
\hline East/South East Asian & 13.3 & 11.7 & 10.8 & 5.6 & 88.3 \\
\hline South Asian & 8.8 & 10.9 & 9.0 & 6.2 & 89.1 \\
\hline Other & 13.2 & 23.7 & 21.9 & 15.2 & 76.3 \\
\hline \multicolumn{6}{|c|}{ Subjective socioeconomic status } \\
\hline Low & 67.3 & 26.3 & 20.6 & 13.1 & 77.0 \\
\hline High & 32.7 & 23.0 & 23.5 & 15.6 & 73.7 \\
\hline \multicolumn{6}{|l|}{ Immigration status } \\
\hline Nonimmigrant & 81.7 & $26.5 \ddagger$ & $23.7 \ddagger$ & $15.4 \ddagger$ & 73.5 \\
\hline Immigrant & 18.3 & 13.4 & 11.6 & 7.6 & 86.6 \\
\hline \multicolumn{6}{|c|}{ Tobacco cigarette use in previous year } \\
\hline No & 81.9 & $11.8 \ddagger$ & $10.0 \ddagger$ & $5.4 \ddagger$ & 88.2 \\
\hline Yes & 18.1 & 80.0 & 73.7 & 53.0 & 20.0 \\
\hline \multicolumn{6}{|c|}{ Alcohol use in previous past year } \\
\hline None/sip & 53.7 & $3.6 \ddagger$ & $2.8 \ddagger$ & $1.8 \ddagger$ & 96.4 \\
\hline Occasional & 19.8 & 27.5 & 23.9 & 13.6 & 72.5 \\
\hline Regular & 26.5 & 63.2 & 57.8 & 39.0 & 36.8 \\
\hline \multicolumn{6}{|c|}{ Met physical activity recommendation } \\
\hline No & 77.9 & 24.0 & 21.7 & 14.0 & 76.0 \\
\hline Yes & 22.1 & 24.6 & 20.9 & 13.8 & 75.4 \\
\hline \multicolumn{6}{|c|}{ Met screen time recommendation } \\
\hline No & 64.3 & 24.6 & 21.9 & 14.7 & 75.4 \\
\hline Yes & 35.7 & 23.3 & 20.8 & 12.7 & 76.7 \\
\hline \multicolumn{6}{|c|}{ Met age-appropriate sleep duration recommendation } \\
\hline No & 64.1 & $26.6 \neq$ & $23.9 \ddagger$ & $15.6 \ddagger$ & 73.4 \\
\hline Yes & 35.9 & 19.6 & 17.3 & 10.9 & 80.4 \\
\hline \multicolumn{6}{|c|}{$\begin{array}{l}\text { Note: SD = standard deviation. } \\
\text { *Data are shown as weighted column percentage in "Total sample" column; weighted row percentage is used elsewhere unless indicated } \\
\text { otherwise. } \\
\text { †Cannabis use measures are dichotomous; however, only "yes" responses are shown. } \\
\neq p<0.05 \text {. }\end{array}$} \\
\hline
\end{tabular}


Research

Table 3: Logistic regression of past-year cannabis use among Ontario middle and high school students by demographic and behavioural factors*

\begin{tabular}{|c|c|c|c|c|}
\hline \multirow[b]{2}{*}{ Factor } & \multicolumn{4}{|c|}{ Model; OR $(95 \% \mathrm{Cl}) \dagger$} \\
\hline & Model 1 , unadjusted & Model 2, adjusted $\ddagger$ & Model 3, adjusted§ & Model 4, adjusted \\
\hline \multicolumn{5}{|l|}{ Sex } \\
\hline Male & 1 & 1 & & 1 \\
\hline Female & $0.90(0.73-1.13)$ & $0.93(0.75-1.14)$ & $0.94(0.73-1.19)$ & $0.91(0.71-1.16)$ \\
\hline \multicolumn{5}{|l|}{ Grade } \\
\hline $7 / 8$ & 1 & 1 & 1 & 1 \\
\hline 9 & 3.65 (1.68-7.94) & $3.67(1.67-8.05)$ & $1.63(0.83-3.21)$ & $1.64(0.85-3.19)$ \\
\hline 10 & $10.63(4.9-22.81)$ & $11.18(5.17-24.16)$ & $3.77(1.98-7.18)$ & $3.71(1.96-7.04)$ \\
\hline 11 & $17.24(8.07-36.81)$ & 17.51 (8.13-37.69) & $3.75(1.97-7.12)$ & 3.66 (1.94-6.92) \\
\hline 12 & $19.26(8.97-41.36)$ & $21.15(9.83-45.51)$ & $3.87(2.06-7.26)$ & $3.85(2.07-7.16)$ \\
\hline \multicolumn{5}{|l|}{ Ethnicity } \\
\hline White & 1 & 1 & 1 & 1 \\
\hline Black & $0.98(0.68-1.41)$ & $1.16(0.81-1.66)$ & $2.70(1.77-4.11)$ & $2.67(1.76-4.05)$ \\
\hline East/South East Asian & $0.35(0.26-0.49)$ & $0.43(0.31-0.59)$ & $0.81(0.58-1.14)$ & $0.77(0.54-1.10)$ \\
\hline South Asian & $0.29(0.21-0.41)$ & $0.31(0.22-0.44)$ & $0.94(0.58-1.52)$ & $0.92(0.56-1.50)$ \\
\hline Other & $0.82(0.67-1.01)$ & $1.01(0.78-1.31)$ & $1.18(0.81-1.72)$ & $1.16(0.79-1.71)$ \\
\hline \multicolumn{5}{|c|}{ Subjective socioeconomic status } \\
\hline High & 1 & 1 & 1 & 1 \\
\hline Low & $1.19(0.98-1.43)$ & $1.13(0.94-1.34)$ & $1.03(0.85-1.26)$ & $1.01(0.83-1.22)$ \\
\hline \multicolumn{5}{|l|}{ Immigration status } \\
\hline Nonimmigrant & 1 & 1 & 1 & 1 \\
\hline Immigrant & $0.42(0.32-0.56)$ & $0.48(0.37-0.64)$ & $0.56(0.39-0.79)$ & $0.55(0.39-0.78)$ \\
\hline \multicolumn{5}{|c|}{ Tobacco cigarette use in previous year } \\
\hline No & 1 & & 1 & 1 \\
\hline Yes & $25.18(20.58-30.81)$ & & $10.90(8.60-13.83)$ & $10.10(8.68-13.92)$ \\
\hline \multicolumn{5}{|l|}{ Alcohol use in previous year } \\
\hline None/sip & 1 & & 1 & 1 \\
\hline Occasional & $10.94(8.24-14.52)$ & & $5.42(4.08-7.21)$ & $5.35(4.01-7.13)$ \\
\hline Regular & $47.53(35.53-63.58)$ & & $14.84(10.87-20.26)$ & $14.6(10.8-19.89)$ \\
\hline \multicolumn{5}{|c|}{ Met physical activity recommendation } \\
\hline No & $1.05(0.88-1.25)$ & & & $1.10(0.87-1.38)$ \\
\hline Yes & 1 & & & 1 \\
\hline \multicolumn{5}{|c|}{ Met screen time recommendation } \\
\hline No & $1.07(0.91-1.26)$ & & & $1.09(0.82-1.45)$ \\
\hline Yes & 1 & & & 1 \\
\hline \multicolumn{5}{|c|}{ Met sleep duration recommendation } \\
\hline No & $1.50(1.25-1.81)$ & & & $1.21(0.95-1.55)$ \\
\hline Yes & 1 & & & 1 \\
\hline \multicolumn{5}{|c|}{$\begin{array}{l}\text { Note: } \mathrm{Cl}=\text { confidence interval, } \mathrm{OR}=\text { odds ratio. } \\
\text { "Models compare past-year cannabis use to no use. } \\
\text { †Bolded values significant at } p<0.05 \text {. } \\
\text { †Adjusted for sex, grade, ethnicity, socioeconomic status and immigration status. } \\
\text { §Adjusted for sex, grade, ethnicity, socioeconomic status, immigration status, tobacco cigarette use and alcohol use. } \\
\text { qAdjusted for sex, grade, ethnicity, socioeconomic status, immigration status, tobacco cigarette use, alcohol use, and adherence to the physical activity, screen time and } \\
\text { sleep duration recommendations. }\end{array}$} \\
\hline
\end{tabular}


factors. Analyses adjusted for demographic characteristics (model 2) indicated that cannabis use in the previous year was associated with grade in a dose-response fashion, with older students being more likely than younger students to use cannabis. Both being from an Asian background and being an immigrant were associated with lower odds of cannabis use (model 2). Further adjustment for substance use in addition to sociodemographic characteristics changed the link between cannabis use and being black to significance (model 3). Smoking tobacco cigarettes and drinking alcohol regularly or occasionally were also associated with greater odds of cannabis use (model 3). In the fully adjusted model (model 4), being in grades 10 through 12, being black, smoking tobacco cigarettes and drinking alcohol regularly or occasionally were associated with greater odds of cannabis use. In contrast, being an immigrant was associated with lower odds of cannabis use.

\section{Interpretation}

Using data from the 2015 cycle of the Ontario Student Drug Use and Health Survey to investigate the prevalence and sociodemographic and behavioural correlates of cannabis use among middle and high school students in Ontario, we found that, overall, $21.5 \%$ of students, representing about 204000 students in grades 7-12 in Ontario, reported cannabis use in the previous year. Some students $(6.5 \%)$ reported having tried cannabis for the first time as early as elementary school, which emphasizes the importance of early interventions. Being a regular alcohol user and using tobacco cigarettes were the strongest predictors of cannabis use. There was a significant dose-response gradient with age, with older students being more likely to use cannabis than younger students. Being in grades 10 through 12 and being black were also associated with greater odds of cannabis use. Being an immigrant was associated with lower odds of cannabis use.

The prevalence of past-year cannabis use is consistent with the national estimate of $20.6 \%$ among adolescents aged 15-19 years using data from the 2014/15 Canadian Student Tobacco, Alcohol and Drugs Survey ${ }^{18}$ and with data for youth aged 15-17 years from the Canadian Community Health Survey $(20 \%) .{ }^{19}$ Our estimates are also somewhat consistent with data for students in grades 8, 10 and 12 in the United States who participated in the 2015 (23.7\%) and 2016 (22.6\%) Monitoring the Future survey. ${ }^{20}$ It does appear that cannabis use is lower in Canada than in the US. For example, results from the 2015 cycle of the US Youth Risk Behaviour Surveillance System show lifetime and past-month prevalence rates of cannabis use of $38.6 \%$ and $21.7 \%$, respectively. ${ }^{21}$ Although a recent report indicated that cannabis use in Ontario decreased over the past 2 decades, from $28.0 \%$ in 1999 to $21.3 \%$ in $2015,{ }^{12}$ there have been increases in heavy use. For example, the prevalence of daily or near-daily use among adults in the US rose from $1.9 \%$ in 2002 to $3.5 \%$ in 2015 . And, since 2008 , there have been consistent increases in cannabis use among those aged more than 12 years, particularly in states that allow recreational marijuana. ${ }^{22}$ With the impending legalization of marijuana in Canada, it is possible that access to marijuana and its quality and content will change substantially in the next few years. The tetrahydrocannabinol content of marijuana has already changed (increased) drastically in recent years. $^{23}$

Consistent with other studies that have examined cannabis use in relation to other substances, ${ }^{24-26}$ our results indicate that cannabis use is strongly associated with tobacco cigarette smoking and alcohol drinking. This suggests that cannabis use should be targeted as part of a multicomponent prevention plan that also includes tobacco and alcohol. The observed dose-response gradient with age is consistent with findings of other studies. ${ }^{27,28}$ Also consistent with other reports, ${ }^{29}$ black adolescents were more likely than those of other ethnic backgrounds to report cannabis use. Although Hamilton and colleagues ${ }^{30}$ did not found such link, our results show that this association was driven mainly by other substance use, including alcohol use and tobacco cigarette smoking. The finding that being an immigrant was associated with lower odds of cannabis use also corroborates previous findings and provides further support for the immigrant paradox phenomenon. ${ }^{31,32}$ These results support previous evidence suggesting that ethnoracial background should be an important consideration in investigations of cannabis use among foreign-born compared with nativeborn adolescents. ${ }^{30}$

\section{Strengths and limitations}

The results of this study should be considered in light of the following limitations. First, the study was cross-sectional, so causal inferences cannot be made. Second, the study relied on self-reported data, which may raise potential issues related to social desirably bias, since cannabis is still considered an illicit substance. Third, the study may actually underestimate the prevalence of cannabis use among adolescents, considering that those who have dropped out of school may have particularly high rates of frequent cannabis use. ${ }^{33}$ Finally, although the class response rate was high $(88 \%)$, the student participation rate was relatively low $(59 \%)$ and may have negatively affected the external validity of the results. However, the data did not show evidence of appreciable nonresponse bias. ${ }^{12}$

\section{Conclusion}

This study shows that cannabis use is prevalent among middle and high school students in Ontario and is strongly associated with alcohol drinking and tobacco cigarette smoking. These findings can help to inform physicians and other health care professionals about protective and risk factors associated with cannabis use and can help to identify target groups for future interventions. The findings can also help to inform public health organizations for heightened and tailored school-based prevention efforts. Future research should document trends in cannabis use over time, including its risks, especially with the impending legalization of recreational cannabis. 


\section{References}

1. Silins E, Horwood LJ, Patton GC, et al.; Cannabis Cohorts Research Consortium. Young adult sequelae of adolescent cannabis use: an integrative analysis. Lancet Psychiatry 2014;1:286-93.

2. Volkow ND, Baler RD, Compton WM, et al. Adverse health effects of marijuana use. NEngl 7 Med 2014;370:2219-27.

3. Di Forti M, Morrison PD, Butt A, et al. Cannabis use and psychiatric and cognitive disorders: The chicken or the egg? Curr Opin Psychiatry 2007;20:228-34.

4. Shapiro GK, Buckley-Hunter L. What every adolescent needs to know: cannabis can cause psychosis. 7 Psychosom Res 2010;69:533-9.

5. Lubman DI, Cheetham A, Yücel M. Cannabis and adolescent brain development. Pharmacol Ther 2015;148:1-16.

6. Copeland J, Rooke S, Swift W. Changes in cannabis use among young people: impact on mental health. Curr Opin Psychiatry 2013;26:325-9.

7. MacCoun RJ, Mello MM. Half-baked - the retail promotion of marijuana edibles. NEngl 7 Med 2015;372:989-91.

8. Okaneku J, Vearrier D, McKeever RG, et al. Change in perceived risk associated with marijuana use in the United States from 2002 to 2012. Clin Toxicol (Phila) 2015:53:151-5.

9. Wang GS, Roosevelt G, Heard K. Pediatric marijuana exposures in a medical marijuana state. 7AMA Pediatr 2013;167:630-3

10. Qidwai $W$, Ishaque $S$, Shah $S$, et al. Adolescent lifestyle and behaviour: a survey from a developing country. PLoS One 2010;5:e12914.

11. Fischer B, Russell C, Sabioni P, et al. Lower-risk cannabis use guidelines: a comprehensive update of evidence and recommendations. Am 7 Public Health 2017;107:e1-12.

12. Boak A, Hamilton HA, Adlaf EM, et al. Drug use among Ontario students, 19772015: detailed OSDUHS findings. CAMH Research Document series no. 41. Toronto: Centre for Addiction and Mental Health; 2015.

13. Mokrysz C, Freeman TP, Korkki S, et al. Are adolescents more vulnerable to the harmful effects of cannabis than adults? A placebo-controlled study in human males. Transl Psychiatry 2016;6:e961.

14. Sampasa-Kanyinga H, Chaput JP. Use of social networking sites and alcohol consumption among adolescents. Public Health 2016;139:88-95.

15. Tremblay MS, Warburton DE, Janssen I, et al. New Canadian physical activity guidelines. Appl Physiol Nutr Metab 2011;36:36-46, 47-58.

16. Tremblay MS, Carson V, Chaput JP, et al. Canadian 24-hour movement guidelines for children and youth: an integration of physical activity, sedentary behaviour, and sleep. Appl Physiol Nutr Metab 2016;41(Suppl 3):iii-iv.

17. Hirshkowitz M, Whiton K, Albert SM, et al. National Sleep Foundation's sleep time duration recommendations: methodology and results summary. Sleep Health 2015;1:40-3.

18. Leos-Toro C, Reid JL, Madill CL, et al. Tobacco use in Canada: patterns and trends. Special supplement: Cannabis in Canada. Waterloo (ON): Propel Centre for Population Health Impact, University of Waterloo; 2017. Available: https:// uwaterloo.ca/tobacco-use-canada/sites/ca.tobacco-use-canada/files/uploads/ files/cannabissupplement_2017_final_accessible.pdf(accessed 2017 Jan. 7).

19. Rotermann M, Langlois K. Prevalence and correlates of marijuana use in Canada, 2012. Health Rep 2015;26:10-5.

20. Miech RA, Johnston LD, O'Malley PM, et al. Monitoring the future: national survey results on drug use, 1975-2016. Vol. I: Secondary school students. Ann Arbor (MI): Institute for Social Research, University of Michigan; 2017. Available: http://monitoringthefuture.org/pubs.html\#monographs (accessed 2017 Aug. 11).

21. Kann L, McManus T, Harris WA, et al. Youth risk behavior surveillance United States, 2015. MMWR Surveill Summ 2016;65:1-174.

22. World drug report 2017. Vienna: United Nations Office on Drugs and Crime; 2017.

23. A framework for the legalization and regulation of cannabis in Canada: the final report of the Task Force on Cannabis Legalization and Regulation. Ottawa: Health Canada; 2016. Available: https://www.canada.ca/en/services/ health/marijuana-cannabis/task-force-marijuana-legalization-regulation/ framework-legalization-regulation-cannabis-in-canada.html (accessed 2018 Jan. 8).
24. Suris JC, Akre C, Berchtold A, et al. Some go without a cigarette: characteristics of cannabis users who have never smoked tobacco. Arch Pediatr Adolesc Med 2007;161:1042-7.

25. Coffey C, Lynskey M, Wolfe R, et al. Initiation and progression of cannabis use in a population-based Australian adolescent longitudinal study. Addiction 2000;95:1679-90.

26. Brook JS, Lee JY, Brook DW. Trajectories of marijuana use beginning in adolescence predict tobacco dependence in adulthood. Subst Abus 2015;36:470-7.

27. Johnston LD, O'Malley PM, Miech RA, et al. Monitoring the future: national results on drug use: 1975-2014 - overview, key findings on adolescent drug use. Ann Arbor (MI): Institute For Social Research, University Of Michigan; 2014. Available: www.monitoringthefuture.org/pubs/monographs/mtf-overview2014.pdf (accessed 2018 Jan. 7).

28. Palmer RHC, Young SE, Hopfer CJ, et al. Developmental epidemiology of drug use and abuse in adolescence and young adulthood: evidence of generalized risk. Drug Alcobol Depend 2009;102:78-87.

29. Johnson RM, Fairman B, Gilreath T, et al. Past 15-year trends in adolescent marijuana use: differences by race/ethnicity and sex. Drug Alcohol Depend 2015; 155:8-15.

30. Hamilton HA, Owusu-Bempah A, Boak A, et al. Ethnoracial differences in cannabis use among native-born and foreign-born high school students in Ontario. F Ethn Subst Abuse 2017 May 10 [Epub ahead of print]. doi:10.1080/1 5332640.2017 .1312655 .

31. Chun H, Mobley M. The "immigrant paradox" phenomenon: assessing problem behaviors and risk factors among immigrant and native adolescents. 7 Prim Prev 2014;35:339-56.

32. Cristini F, Scacchi L, Perkins DD, et al. Drug use among immigrant and non-immigrant adolescents: immigrant paradox, family and peer influences. $\mathcal{F}$ Community Appl Soc Psychol 2015;25:531-48.

33. Bray JW, Zarkin GA, Ringwalt C, et al. The relationship between marijuana initiation and dropping out of high school. Health Econ 2000;9:9-18.

Affiliations: School of Epidemiology and Public Health (SampasaKanyinga), University of Ottawa, Ottawa, Ont.; Institute for Mental Health Policy Research (Hamilton), Centre for Addiction and Mental Health; Dalla Lana School of Public Health (Hamilton), University of Toronto, Toronto, Ont.; Division of Prevention and Rehabilitation (LeBlanc), University of Ottawa Heart Institute; Healthy Active Living and Obesity Research Group (Chaput), Children's Hospital of Eastern Ontario Research Institute, Ottawa, Ont.

Contributors: Hugues Sampasa-Kanyinga performed the statistical analyses. Hugues Sampasa-Kanyinga and Allana LeBlanc drafted the manuscript. Hayley Hamilton is a coinvestigator of the survey on which the analyses are based. All of the authors contributed to the conception and design of the study and the interpretation of the data, revised the manuscript critically for important intellectual content, gave final approval of the version to be published and agreed to be accountable for all aspects of the work.

Funding: The Ontario Student Drug Use and Health Survey, an initiative of the Centre for Addiction and Mental Health, was funded in part through ongoing support from the Ontario Ministry of Health and LongTerm Care as well as targeted funding from several provincial agencies. The funders had no involvement in study design; collection, analysis or interpretation of data; writing the manuscript; or the decision to submit the manuscript for publication.

Supplemental information: For reviewer comments and the original submission of this manuscript, please see www.cmajopen.ca/content/6/1/ E50/suppl/DC1. 